\title{
Management and research applications of real-time and archival passive acoustic sensors over varying temporal and spatial scales
}

\author{
Sofie M. Van Parijs ${ }^{1, *}$, Chris W. Clark ${ }^{2}$, Renata S. Sousa-Lima ${ }^{2,3}$, Susan E. Parks ${ }^{4}$, \\ Shannon Rankin ${ }^{5}$, Denise Risch ${ }^{1,6}$, Ilse C. Van Opzeeland ${ }^{7}$ \\ ${ }^{1}$ Northeast Fisheries Science Center, 166 Water Street, Woods Hole, Massachusetts 02543, USA \\ ${ }^{2}$ Bioacoustics Research Program, Cornell Lab. of Ornithology, Sapsucker Woods Road, Ithaca, New York 14850, USA \\ ${ }^{3}$ Instituto Baleia Jubarte, Rua Barão do Rio Branco, 26, Caravelas, BA 45900-000, Brazil \\ ${ }^{4}$ The Pennsylvania State University, Applied Research Laboratory, PO Box 30, State College, Pennsylvania 16804-0030, USA \\ ${ }^{5}$ Southwest Fisheries Science Center, 3333 N. Torrey Pines Court, La Jolla, California 92037, USA \\ ${ }^{6}$ Integrated Statistics, 9 Sumner Road, Woods Hole, Massachusetts 02543, USA \\ ${ }^{7}$ Alfred Wegener Institute for Polar and Marine Research, Department of Ocean Acoustics, Am Alten Hafen 26, \\ 27568 Bremerhaven, Germany
}

\begin{abstract}
Defining the appropriate scale over which to conduct a study in the marine environment is critical to achieving appropriate scientific, management, mitigation and conservation objectives. This paper focuses on applications of passive acoustic technologies over a range of spatial and temporal scales. It is divided into sections dealing with archival and real-time passive acoustic sensor applications. Each section assesses the principles behind using the respective technology and provides recent examples of research and management applications for marine mammals and fish. The section on archival sensors highlights the need for continued development of automated acoustic detectors to assess large data sets. Case studies are presented of detectors developed for determining seasonal occurrence and distribution of haddock sounds and humpback whale vocalizations. Also presented are studies of other applications using archival sensors: tracking singing humpback whales in Brazil, using vocalizations to assess the reproductive strategies of Arctic bearded seals and assessing regional variability in call patterns for North Atlantic right whales. The section on real-time passive acoustic sensors focuses on real-time buoys and towed arrays. Case studies presented include a real-time buoy system used for monitoring endangered North Atlantic right whales and a stationary autonomous array providing real-time access to Antarctic acoustic data. The value of using towed arrays for real-time applications is also assessed, and a case study is provided on the use of towed arrays to improve abundance estimates of North Pacific cetaceans and to better understand vocalization behaviors.
\end{abstract}

KEY WORDS: Passive acoustics - Mesoscale $\cdot$ Archival arrays - Real-time buoys · Towed arrays · Localization $\cdot$ Automated detection $\cdot$ Marine mammals $\cdot$ Fish

\section{INTRODUCTION}

The task of scientists, managers and mitigators alike is to use the right set of tools at the right spatial scale for the issue that needs addressing. To do this efficiently and effectively is no easy task, yet it is essential.
Spatial scaling has long been an acknowledged driver defining research questions within the atmospheric and earth sciences. However, it is a more recent concept for ecologists, the value of which is increasingly becoming understood (Wiens 1989). Accurately describing and understanding the processes that deter- 
mine the distribution of organisms is a fundamental problem in ecology, with important conservation and management implications (Redfern et al. 2006). The terms 'synoptic' or large-scale, 'meso' or medium-scale and 'micro' or small-scale have most frequently been used in meteorology and oceanography, where descriptors of weather systems need to be provided at local, regional, continental and global scales (e.g. Capet et al. 2008). This terminology is also valuable when searching for meaningful spatial descriptors of the marine environment, particularly in relation to the movement patterns of biological entities that live within it. The terminology itself is somewhat arbitrary and needs to be taken in the context of each specific situation. Here we define synoptic scales for regional marine areas of $>2000 \mathrm{~km}^{2}$, mesoscale as areas between 1 and $2000 \mathrm{~km}^{2}$ in size and microscales as areas $<1 \mathrm{~km}^{2}$ (Orlanski 1975).

Marine animals live their lives and communicate acoustically across widely differing spatial scales. Large whales range and can communicate over microto synoptic scales (Moore et al. 2006), while smaller whales and dolphins tend to range and communicate over micro- to mesoscale areas (e.g. Tyack 2000). Pinnipeds are bound to land for breeding and moulting; therefore, access to land or ice is a fixture of their life histories. Acoustic behavior in pinnipeds has been shown to range from local $(<1 \mathrm{~km})$ to mesoscales with communication occurring both in air and in the water near haul-out sites on transit routes and foraging grounds (e.g. Insley et al. 2003, Van Parijs 2003). Sirenian vocalizations tend to be more localized than those of cetaceans and pinnipeds. Although movements of manatees may exceed $820 \mathrm{~km}$ (Reid et al. 1991), their communication range is short, with sounds limited to distress calls or to identify, locate or maintain proximity between mothers and calves (Sousa-Lima et al. 2002a, 2008). Dugongs may use their vocalizations at slightly longer distances while patrolling their territory (Anderson \& Barclay 1995). Fish routinely produce sounds for long periods of time, allowing for seasonal and diurnal tracking of large shoals, and communicate over ranges of a few hundred meters up to $8 \mathrm{~km}$ (e.g. Saucier \& Baltz 1993, Mann \& Lobel 1995, Luczkovich et al. 1999, 2008, McCauley \& Cato 2000).

Most marine management and conservation areas, zones, parks or sanctuaries tend to be micro- or mesoscale in size. Management areas rarely encompass the entire range of the biota and are generally targeted towards areas where important biological activities occur. Similarly, scientific studies are typically practical only at micro- or mesoscales, because studies conducted on ocean-basin scales remain logistically and financially prohibitive to most institutions (see Mellinger et al. 2007). These relatively small scalar approaches mean that little is still understood about how marine animals use the synoptic scale and how significant this scale is in terms of their management and conservation.

Passive acoustic monitoring (PAM) encompasses a functional suite of tools that can answer scientific questions and influence management and/or mitigation applications over all spatial scales. The tools that are available to acquire and analyze passive acoustic data have undergone a revolutionary change over the last decade, and have substantially increased our ability to collect acoustic information and use it as a functional management tool. Recent reviews of the passive acoustic technologies currently available concentrate both on cetaceans (Mellinger et al. 2007), pinnipeds (Van Opzeeland et al. 2008) and fish (Gannon 2008, Luczkovich et al. 2008). The present study focuses on the value of using bottom-mounted buoys, towed arrays and real-time acoustic sensors for both scientific and management applications with respect to acoustically active marine animals over a wide range of spatial scales. We divide this article into 2 sections based on available passive acoustic sensors: archival and real-time. Each section discusses the applications of these technologies and provides case studies related to the application. To date, the majority of applications of these technologies have focused on cetacean research, management and/or mitigation. However, the value of using similar applications for pinnipeds, sirenians and fish has yet to be fully realized. In the present study we provide case studies of applications for most taxa.

\section{ARCHIVAL PASSIVE ACOUSTIC SENSORS}

Mellinger et al. (2007) and Van Opzeeland et al. (2008) provide reviews of the types of archival marine acoustic recording units (ARUs) that are currently available for both science and management purposes. ARUs vary widely in type, from stationary units consisting of single or multiple hydrophones, a single hydrophone deployed on an individual animal, to multiple sensors on towed or bottom-mounted hydrophone arrays. Therefore, the spatial scale and breadth of coverage of acoustically active marine animals varies widely, depending on the type of sensor that is used (Fig. 1a).

As the technical capabilities of such units have improved and costs have decreased, it has become increasingly feasible to deploy multiple recorders in the form of acoustic arrays ( $\geq 3$ ARUs). This, in turn, has enabled an increase in the accuracy of the data collected and the number of individuals surveyed (Fig. 1b). Collecting passive acoustic data on multiple channels makes it possible to detect, localize and track vocalizing fish and marine mammals. To do so accu- 


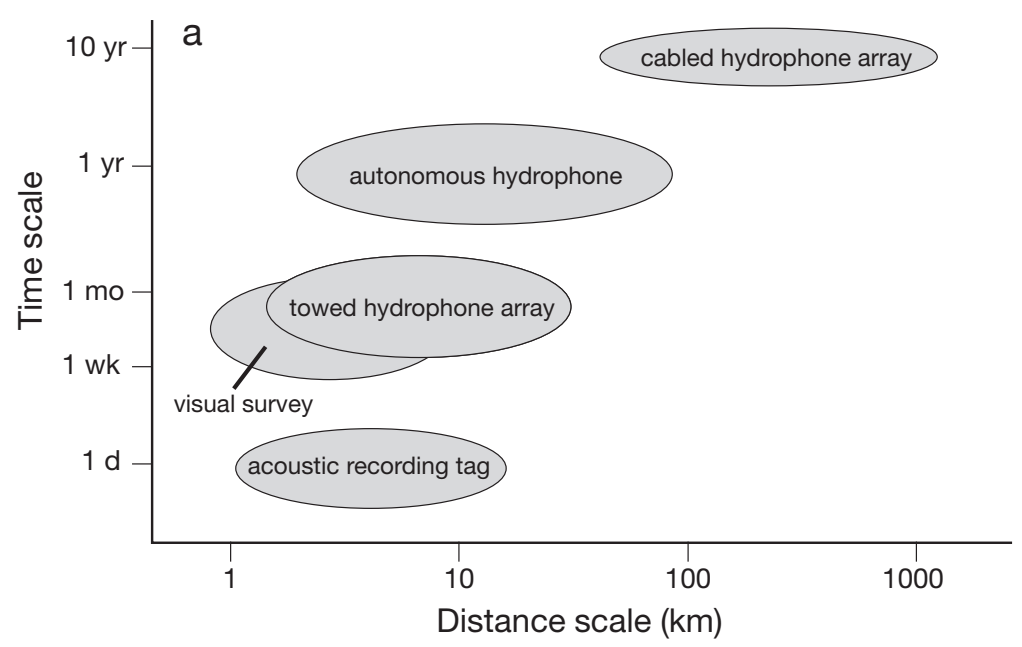

b

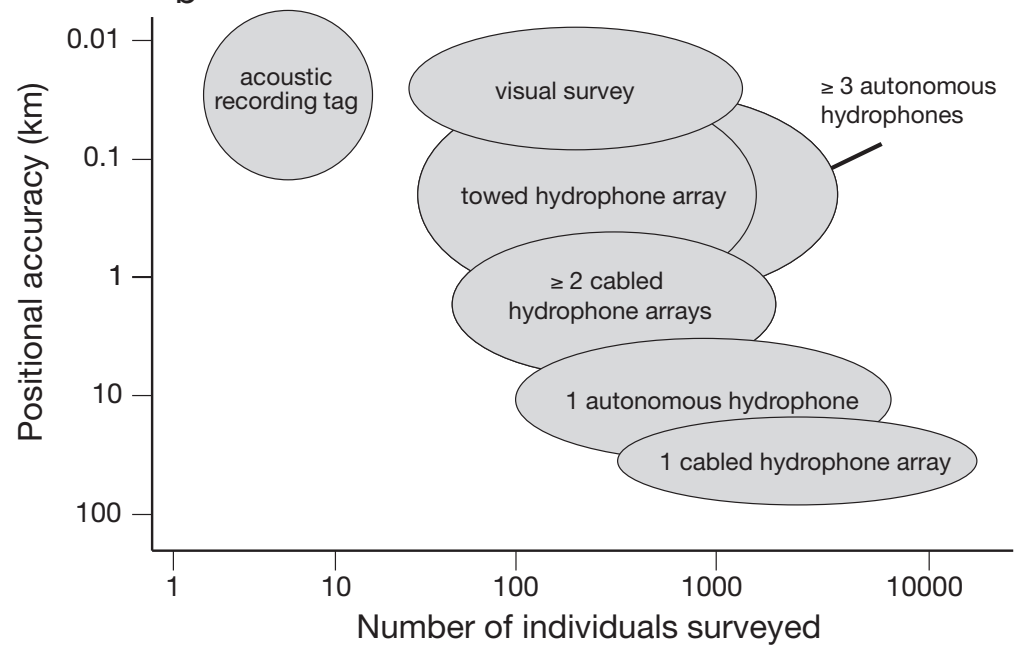

Fig. 1. (a) Approximate temporal and spatial scales over which data are collected using an acoustic recording tag on a single individual, an autonomous hydrophone, a vessel towed array and a bottom-mounted cabled hydrophone array. These acoustic techniques are compared with the temporal and spatial scope of visual surveys. (b) Approximate range of accuracy and number of individuals covered using an acoustic recording tag on an individual animal, an autonomous hydrophone, a vessel towed array composed of $\geq 3$ hydrophones and $\geq 2$ bottommounted cabled hydrophone arrays. Figures were provided courtesy of D. K. Mellinger

rately requires precise time synchronization of all the channels and can be logistically difficult when using separate sensors as opposed to systems such as towed arrays that simultaneously log multi-channel data. However, if done properly, acoustic arrays can improve understanding of species distributions and densities over varying temporal and spatial scales. Such arrays have been routinely used to study cetaceans (e.g. Moore et al. 2006, Mellinger et al. 2007). More recently, their utility has also been shown for investigating long-term behavioral strategies in pinnipeds (e.g.
Van Parijs 2003, Van Opzeeland et al. 2008). However, the data collected by ARUs can easily run into multiple terabytes in size. Thus the first step to accessing data from both archival and real-time ARUs is to find the sounds of interest. It is logistically impossible to hand browse these types of data sets. Therefore, there is an increased need for suitable acoustic detection and recognition software to deal with this problem. Several valuable tools already exist to do this (e.g. Ishmael: Mellinger \& Clark 2006, www.pmel. noaa.gov/vents/acoustics/whales/ishmael; Pamguard: Urazghildiiev \& Clark 2006, www. pamguard.org; XBAT: Figueroa 2006, www. xbat.org); however, it is vital to realize that a solid understanding of the acoustic behavioral ecology of each species is imperative to using these tools appropriately. Without an understanding of a species' acoustic repertoire, call patterning, individual and group calling behavior as well as seasonal and regional variation in call usage, no clear or coherent research or management question can be addressed.

In the following we provide examples over a range of spatial scales of how archival acoustic sensors can be used to study the behavioral ecology of vocal marine animals. Our aim is to provide an understanding of the tools and methodologies that are currently available to address a range of ecological questions directed towards improving marine animal management, mitigation and conservation strategies.

\section{Regional differences in North Atlantic right whale acoustic patterns and call types throughout the northwestern Atlantic Ocean}

Collecting acoustic data over large spatial and temporal scales is becoming increasingly commonplace. The value of increased data collection over larger scales is indisputable in terms of understanding and managing populations more effectively. However, marine animal behavior varies considerably between seasons and over geographical areas. Therefore, it is no surprise that their acoustic behavior is equally variable, driven by varying life history parameters and experiences at the individual, population and species level. When using acoustics to implement management and mitigation strategies for a species it is imperative to understand their call repertoire and whether this varies regionally. 
In the case of the endangered North Atlantic right whale Eubalaena glacialis, acoustic monitoring can be a valuable tool for both management and conservation. Ship strike is one of the main anthropogenic causes of mortality in this species (e.g. Silber \& Bettridge 2006), and reducing the likelihood of strikes in high vessel traffic areas is of primary concern. Low reproductive rates are also a major factor limiting their recovery, although calf production has increased during the past $6 \mathrm{yr}$ (Kraus et al. 2005). Identification and protection of the mating grounds for this species may also be an important step toward their conservation. However, the location of the majority of the population during the breeding season (presumed to peak in OctoberDecember) remains unknown (Weinrich et al. 2000, IWC 2001, Kraus \& Hatch 2001). Passive acoustic monitoring can monitor areas of high risk and investigate remote inaccessible areas for the presence of right whales.

The upcall, or contact call, is typically the call type used for diagnostic detection of right whale species (Wade et al. 2006, Clark et al. 2007). This call is highly stereotypic making it ideal for species recognition. Studies of the behavioral function of sounds in the right whale repertoire have identified 2 additional classes of sounds, tonal calls and gunshot sounds, related to social and/or mating activity (Parks \& Tyack 2005) and potential male reproductive signals (Parks et al. 2005). In order to develop an effective management or monitoring scheme and search large quantities of acoustic data for the presence of a given species, it is important to understand whether to use a single call type or a combination of several call types. To make this decision a good understanding of regional patterns and call type usage in the target species is needed.

In the present North Atlantic right whale study, bottom-mounted ARUs were deployed in 3 known right whale habitat areas (Cape Cod Bay, Massachusetts; the Great South Channel, approximately 50 nautical miles offshore from Massachusetts; and the Bay of Fundy; see habitat descriptions in Kraus \& Kenney 1991, Brown et al. 1995) to determine whether regional differences existed in the vocal behavior of the whales. The first 2 habitats have been shown to be frequented by large numbers of right whales during the spring, and the latter is primarily used in summer months. Data were collected during a short period within each of these peak periods ( $8 \mathrm{~d}$ in Cape Cod Bay between 1 March and 10 April 2004, 5 d in the Great South Channel between 12 and 17 May 2004 and $8 \mathrm{~d}$ in the Bay of Fundy between 7 and 24 August 2004). The Cape Cod Bay array consisted of 4 units, while the Great South Channel and Bay of Fundy arrays consisted of 5 units each. ARUs were spaced 3 to 5 nautical miles apart to allow for maximal acoustic survey area with the ability to localize vocalizations within the array itself. Sampling rate was between 2 and $8 \mathrm{kHz}$. The recordings were inspected for right whale calls using XBAT and labeled as upcalls, other tonal calls or gunshot sounds. Analyses of the call types across the 3 habitat areas show a clear difference in the calling behavior of right whales in the spring versus the summer habitat areas (Fig. 2). Gunshots accounted for a significantly larger proportion of total detected sounds in the Bay of Fundy than in either Cape Cod Bay or the Great South Channel (ANOVA, $F_{2,19}=54.9$, $\mathrm{p}<0.0001$ ). These results suggest that the social interactions of right whales change through the seasons, with an increase in gunshot sounds, thought to be related to reproduction, later in the year. The present study demonstrates the utility of using upcalls as a tool for monitoring the presence of right whales and managing ship strike throughout most regions of the western Atlantic. However, it also suggests that other call types, such as gunshots, may be more effective for indicating right whale presence in some regions, such as their foraging and breeding grounds. This then also begs the question as to how each of these call types is used on the calving grounds. To date, this research has not been undertaken but should be done to validate any management or mitigation strategy for this region. Overlap of call types between species is another concern when using acoustics for single-species management and mitigation. In the case of the North

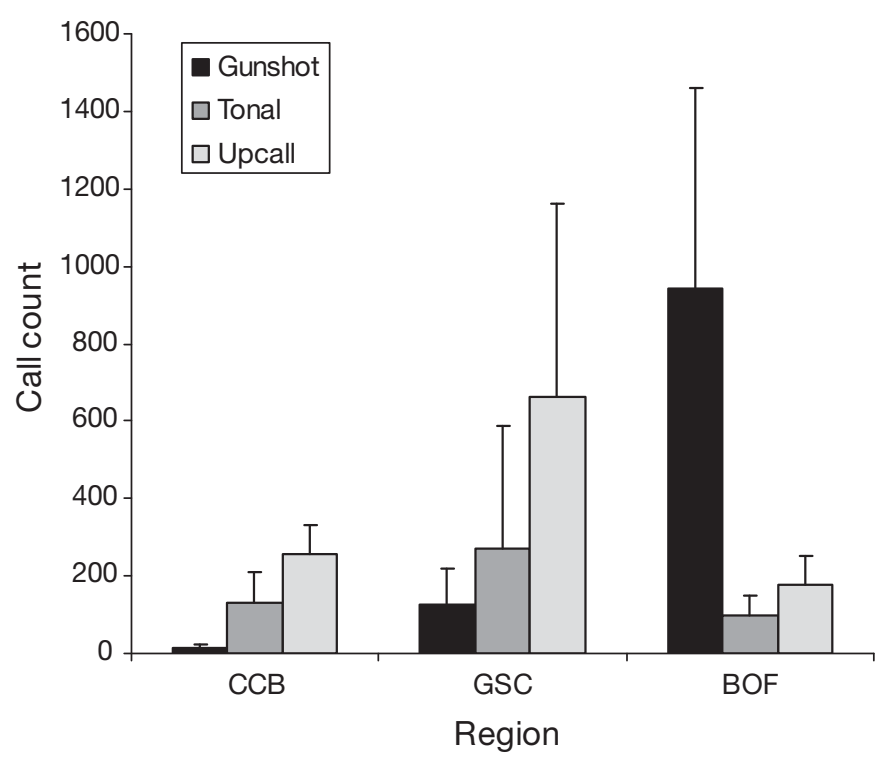

Fig. 2. Archival sea bed acoustic recording units (ARUs) were deployed in 3 North Atlantic right whale habitat areas off the northeast coast of the USA: Cape Cod Bay (CCB), the Great South Channel (GSC) and the Bay of Fundy (BOF). Bars represent the median $( \pm \mathrm{SE})$ of daily call counts broken down by 3 call types (gunshot, tonal and upcall) for each habitat area 
Atlantic right whale, humpback whales are capable of producing upcalls that closely resemble those of right whales. How significant this overlap really is and whether there is potential for differentiation should be explored further.

\section{Acoustic detection of haddock and humpback whale sounds: understanding seasonal distribution and occurrence}

The next step to manage, mitigate and/or conserve a species regionally is to understand its seasonal distribution and occurrence. In order to do this, automated detectors targeting specific call types are needed.

The Gerry E. Studds Stellwagen Bank National Marine Sanctuary, situated in Massachusetts Bay on the northeast coast of the USA, is the research venue of an ambitious multi-year passive acoustic project aimed at developing a suite of tools to monitor and map ocean underwater noise over a mesoscale region (for more project details see Hatch \& Fristrup 2009, this Theme Section). Ten archival ARUs were deployed in 2006 and will remain operational until late 2010․․ By late 2010, more than $400000 \mathrm{~h}$ of acoustic data will have been collected. Given recent technological advances, it is now fairly simple to collect a lot of continuous data over a long time scale. The tools with which to analyze this data are, however, not yet routine or well known. Among the primary tools that are becoming widely used are automated detectors. The present study provides an example of how these tools can be used.

As part of the present study, automated acoustic detection software ('detectors') is being developed to search for specific biological sounds produced by baleen whales and various fish species. Acoustic detectors were built using the automated data template detector tool available in XBAT (www.xbat.org, $\mathrm{H}$. Figueroa). XBAT is an extensible sound analysis application which uses MATLAB as a platform for developing sound analysis tools. 'It is open-source, licensed under the General Public License. Users can access and visualize sounds, browse and search for salient events, and annotate and measure events. Developers can quickly create easy-to-use extensions with a powerful plug-in architecture'. The automated detectors operate using spectrogram cross-correlation of an example event (the template) and the sound file. Several templates can be arranged in presets.

${ }^{1}$ All ARUs mentioned in this and subsequent studies were developed by the Bioacoustics Research Program of the Cornell Laboratory of Ornithology (BRP, www.birds.cornell.edu/brp/ hardware/autonomous-recording-units)
In the present study, multi-species detectors were built for all large whale and fish species in the sanctuary. Here we describe the process of building detectors for 2 of these species. The first application was enumeration of haddock Melanogrammus aeglefinus spawning sounds. The objective in this case was to develop a detector to evaluate the seasonal occurrence and distribution of spawning haddock over multiple years within the study area. Stellwagen Bank Sanctuary forms one of the two primary spawning sites for haddock in the Gulf of Maine (Colton 1972). Thus this area plays an important role in the life-cycle of this species. Passive acoustics can help to gain a better understanding of haddock distribution and general reproductive behavior in this area, in order to better inform conservation and management of this species.

Haddock produce repetitive knocking sounds directly linked to their spawning behavior (Hawkins et al. 1967, Hawkins \& Amorim 2000, Casaretto \& Hawkins 2002). While these sounds are well described from laboratory experiments, little is known of sound production in wild haddock. These sounds comprise 3 types of calls: single, double and multiple knocks (Fig. 3a). All 3 call types were added to a preset. This preset was run against 10 randomly selected days of manually browsed data to estimate its accuracy at detecting spawning sounds. Multiple presets were constructed using different templates until the most accurate one was developed. The mixed call type preset was able to enumerate haddock knocks with an accuracy of $47 \%$, while the accuracy of different templates was 75,82 , and $41 \%$, respectively, for single, double and multiple knock calls.

This case study illustrates that the data template detector can be highly effective in enumerating sound events. The comparatively low accuracy of the template for multiple knock calls was due to a variable repetition rate of single pulses in different versions of this call type. It is therefore easy to perceive that the more stereotypic a vocalization, the better a detector based on cross-correlation will perform. As such, more variable sound types require different detection approaches. For example, rather than enumerating every single vocalization one might instead search for sound events.

Individual male humpback whales Megaptera novaeangliae produce long repetitive song sequences when attracting females and during male-male competition (e.g. Payne \& McVay 1971, Winn \& Winn 1978, Tyack 1981). Humpback whale song is gender-specific and has been shown to change over time scales of a year to several decades (e.g. Noad et al. 2000, Darling \& Sousa-Lima 2005). Improving our understanding of song and how it is used seasonally, in the breeding and feeding grounds as well as along migration routes, will increase our comprehension of how this species uses 
a


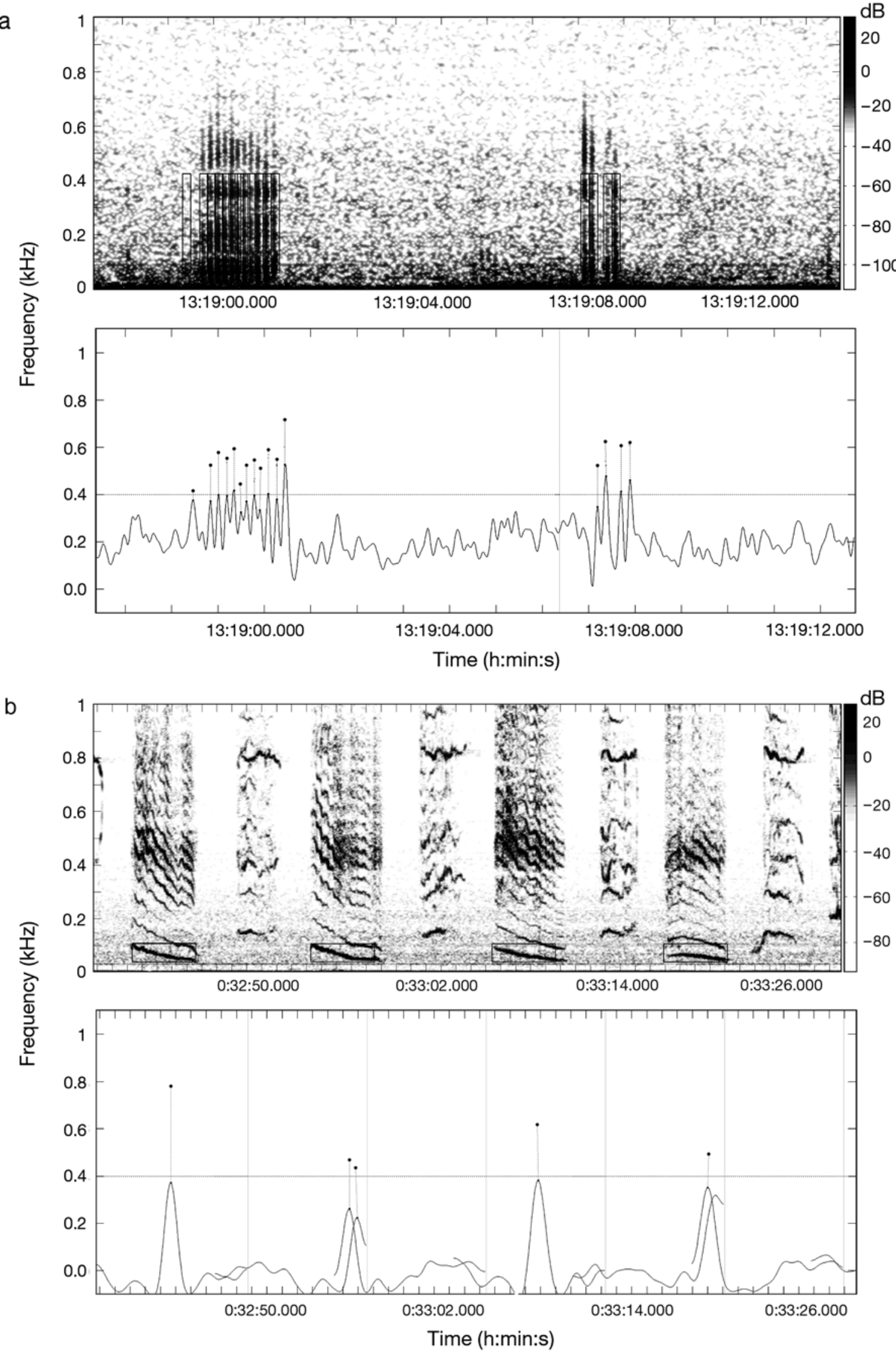
each region as well as how its song evolves both temporally and spatially. Given the variability and length of humpback singing cycles, enumeration of each call type is difficult. However, it is possible to build acoustic detectors that identify song events. In this case, a single call type present in all humpback whale song in the study area during 2006 was selected to build a data preset (Fig. 3b). The resulting preset, based on 5 templates, proved highly effective in detecting hours with humpback whale song throughout 1 yr of acoustic data (89\% accuracy; based on comparison to 4 randomly selected days of hand-browsed data). In the present study, the presence of song within a given hour enabled the determination of song occurrence and distribution over a 12 mo period. Although different from enumeration, this approach is valuable for understanding patterns of sound production. In the case of humpbacks, however, it is important to revisit the efficacy of the detector every year, given that alterations in song may occur. Obviously, it is vital to understand the acoustic behavior of a species since this not only affects the effective operation of a detector but will determine the types of biological and management issues than can be addressed using passive acoustic data. Tools such as the data template detector or existing energy and contour detectors in XBAT and other platforms, which are easy and flexible to use, appear to be the way forward in developing tools and applications for processing acoustic data from multiple species.

\section{Tracking behavioral changes in individual hump- back whales and evaluating anthropogenic effects}

Acoustic localization is a valuable tool for helping to understand the acoustic behavior of an individual or groups of animals. Once baseline individual and/or group behavior is understood, this tool can also be used to assess potential anthropogenic impacts on a species. A multiple year mesoscale study (Sousa-Lima 2007) was conducted at the Abrolhos National Marine Park located in the northeast portion of the Abrolhos Bank off the coast of Brazil $\left(16^{\circ} 40^{\prime}\right.$ to $\left.19^{\circ} 30^{\prime} \mathrm{S}\right)$. In this study an array of 4 bottom-mounted ARUs was used to

Fig. 3. Example of acoustic detections using the data template detector in XBAT for (a) haddock pulsed calls and (b) humpback whale song notes. Lower sections of both examples show the cross-correlation functions. Dotted horizontal line at 0.4 indicates the detection threshold. Every correlation peak above threshold is saved in the detection log. Spectrograms were created with Hanning window. Fast Fourier transform algorithm size: (a) 512, (b) 1024; overlap: (a) $97 \%$, (b) $90 \%$ detect (using similar XBAT sound event detectors as for the study described in the previous section), locate and track multiple singing male humpback whales, as well as to evaluate their behavioral responses to passing tourist boats. Singing whales were located using a custom built localization extension for XBAT (Source Locator version 2.2, K. A. Cortopassi \& K. M. Fristrup unpubl. data). This tool estimates the location of a given signal by calculating the cross-correlation functions between different channels and searching for the best location estimate within a gridded search area. Temporal and spatial changes in the distribution of singing male humpback whales were determined by plotting estimated signal bearings and locations, thus building acoustic tracks of individual whales.

Tracked singers (Fig. 4) were enumerated at multiple points in time to determine whether the numbers of singers changed during periods of variable boat traffic (Sousa-Lima \& Clark 2008). Singers were also acoustically tracked to evaluate whether their movements and vocal behavior changed during the approach of a boat (Sousa-Lima et al. 2002b, Sousa-Lima \& Clark 2009). This study revealed that the scale of the disturbance created by boat traffic to the acoustic environment of humpback whales in the Abrolhos Park is much broader than previously thought. Bottom-mounted arrays are relatively unobtrusive to the animals, and data can be collected over larger spatial and temporal scales. This allows multiple focal individuals to be observed for extended periods of time before, during and after exposure to anthropogenic disturbances.

\section{Understanding reproductive strategies and life history parameters by locating individual bearded seals over decades}

PAM is most frequently thought of in terms of cetacean management and mitigation. However, pinnipeds have never seemed to be suitable candidates for PAM. This case study demonstrates how PAM can be used to provide detailed and long term insights into the reproductive strategies and life history of a pinniped species. The detail is so fine-scale that small-scale changes due to changing environmental conditions are also able to be detected.

Studies of pinniped reproductive strategies have largely concentrated on species which remain ashore during the entire breeding season. However, the Odobenidae and at least 15 of the 18 phocid species mate aquatically (Van Parijs 2003). The use of archival acoustic arrays has significantly advanced our understanding of the reproductive ecology of aquatic mating pinnipeds such as the harbor seal Phoca vitulina (e.g. Van Parijs et al. 2000), the bearded seal Erignathus bar- 


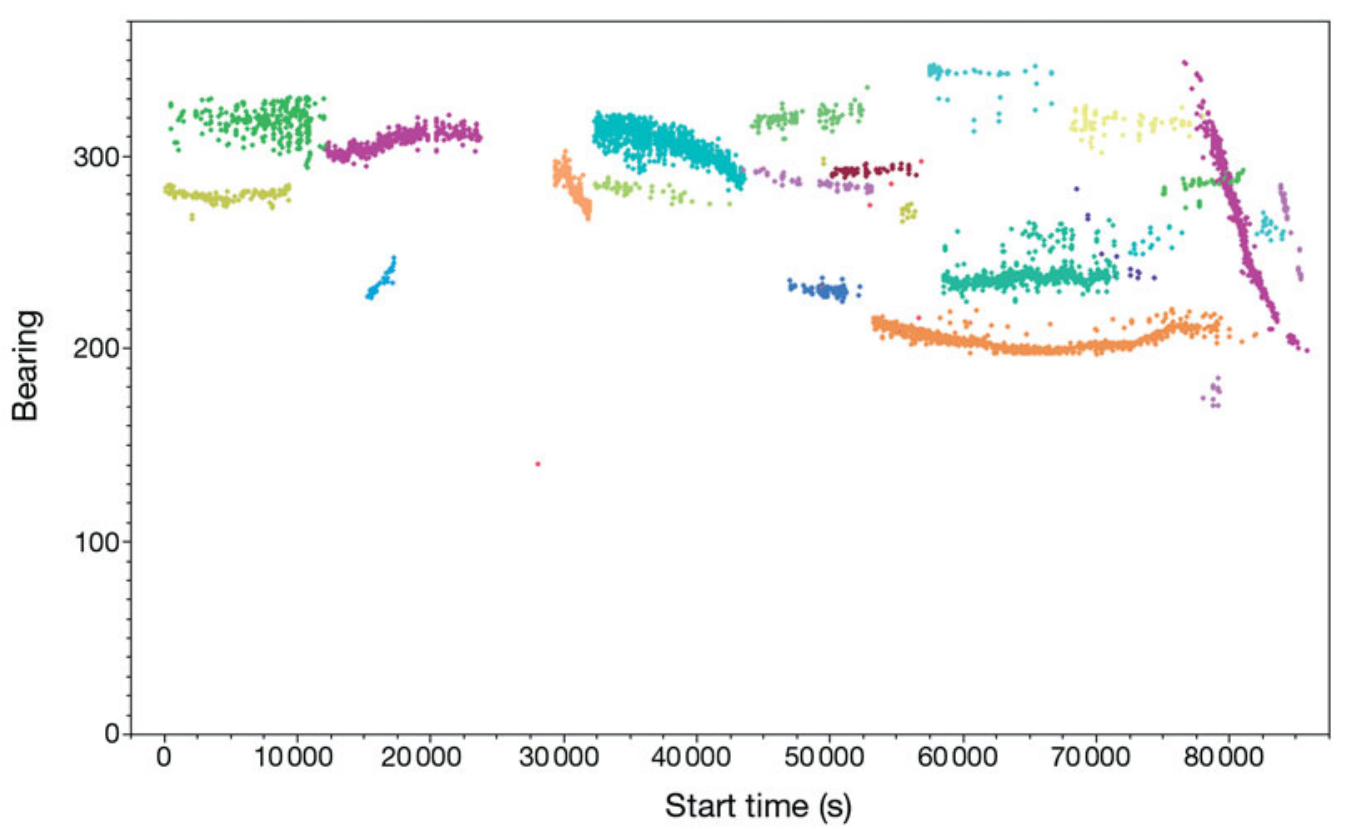

Fig. 4. A synchronized array consisting of 4 archival acoustic recording units was deployed in Abrolhos Park, Brazil. Humpback whale song was localized using XBAT software and the bearings of individuals were plotted. This figure represents plots from a $24 \mathrm{~h}$ sequence and shows the bearings of humpback whale sounds demonstrating how they can be used to make up tracks of multiple singers (distinguished by color)

batus (e.g. Van Parijs et al. 2003, 2004) and Weddell seal Leptonychotes weddellii (e.g. Harcourt et al. 2007).

Archival arrays of 3 to 5 buoys were used to record the trill vocalizations of male bearded seals at 2 Arctic sites, one in the Svalbard archipelago over 2 consecutive years, and one near Barrow, Alaska, over a 16 yr period. Males show stereotypical dive and vocal displays, with clear individual variation (Van Parijs et al. 2003). In Svalbard, acoustic localization provided at-sea locations for 17 males based on variation in trill parameters. Kernel home range analyses showed that 12 individuals displayed at fixed locations (95\% kernels $=0.27$ to $1.93 \mathrm{~km}^{2}$ ), while 5 other males displayed over considerably larger areas (95\% kernels $=5.31$ to $12.5 \mathrm{~km}^{2}$ ) (Fig. 5, Van Parijs et al. 2003). Movement patterns of males suggest that those with small areas patrolled aquatic territories, while those that used larger areas appeared to roam. These data thus provide evidence of alternative mating tactics in this species. In Alaska, acoustic localizations provided at-sea locations for 100 males based on variations in trill parameters, with 6 males being present over the entire 16 yr period (Van Parijs \& Clark 2006). The acoustic data indicate that male mating tactics tend to show long-term stability in vocal characteristics, site fidelity and periods of tenure that cover a significant proportion of a male's adult life span. Ice cover was found to restrict the number of roaming males, whereas territorial males were present during all ice conditions, sug- gesting that varying ice conditions affect individual male strategies and reproductive success (Van Parijs et al. 2004).

Therefore, PAM can provide detailed and long-term information on pinniped species in key areas such as their mating grounds. This information can be so detailed that changes can be detected in individual area usage and behavior as a result of both intraspecific competition and varying environmental conditions.

\section{REAL-TIME PASSIVE ACOUSTIC SENSORS}

To date, discussions of real-time passive acoustic sensors have focused on cabled sea floor mounted hydrophones used mainly by government agencies in particular navies, such as the Sound Surveillance System of the US Navy (SOSUS), which provides realtime information. Mellinger et al. (2007) highlight the benefits of these systems in continuously providing near-real-time data, as well as in having hydrophones in pelagic areas where marine mammal surveys are rare. However, data access and recording bandwidth are usually severely restricted. In recent years, nonmilitary real-time systems have markedly improved and are rapidly becoming a standard technology for use in both research and management. These nonmilitary applications primarily consist of surface buoys or towed arrays; the former tend to consist of single 
units deployed remotely, while the latter depend on vessels for deployment. An increasing number of nonmilitary acoustic observatories are now operational in coastal areas (e.g. the ALOHA Ocean Observatory Network, Petitt et al. 2002, Barnes et al. 2007). These systems (1) allow real-time monitoring and localization of marine animals; (2) record continuously over broad frequency bandwidths; and (3) have no restrictions on data storage, data access or power supply. Surface buoy and towed array applications are discussed in the following sections, and an example is presented of a non-military acoustic observatory.

\section{Real-time surface buoy applications}

Real-time surface buoys are acoustic recording packages anchored to the sea floor but which are connected to floats at the surface which transmit acoustic data via VHF, satellite or mobile phone signals (Fig. 6). The signals sent from these buoys can be transmitted to multiple recipients. The term near real-time is sometimes used in relation to these systems since certain logistical delays are involved in data processing. However, this tool is increasingly approaching real-time functionality.

While real-time buoys are useful tools for research applications, they are increasingly becoming invaluable for implementing management and mitigation strategies. The latter often require action to be taken in as close to realtime as possible for protection measures to be effective. For example, marine mammals can alter their distributions and movements daily, seasonally and annually. Often for management measures to be most effective, reliable real-time information on species distributions is needed. Examples of using real-time data from buoys for mitigation and management purposes include the Gulf of St. Lawrence, where real-time buoy information is being used to mitigate ship strikes of blue whales Balaenoptera musculus and fin whales Balaenoptera physalus (Simard et al. 2006), and along the northeast coast of the USA, where buoy data are being used to mitigate ship strikes of North Atlantic right whales (see following section).

\section{Real-time acoustic monitoring of North Atlantic right whales}

Ship strike mortality remains one of the two primary causes of anthropogenic mortality im- peding the lack of recovery of the endangered North Atlantic right whale (e.g. Silber \& Bettridge 2006). Ship strikes can be reduced by either separating vessels from whales or by decreasing the speed of the vessels (e.g. Vanderlaan \& Taggart 2007). In 1999, NOAA's National Marine Fisheries Service (NMFS) and the US Coast Guard (USCG) established a reporting system that alerts mariners to the location of right whales throughout the East Coast of the US. When vessels greater than 300 gross tons enter these areas they must report to the USCG to receive current sighting information about right whales (Ward-Geiger et al. 2005). To extend the warning system to smaller vessels, the USCG developed another system, called the Auto-
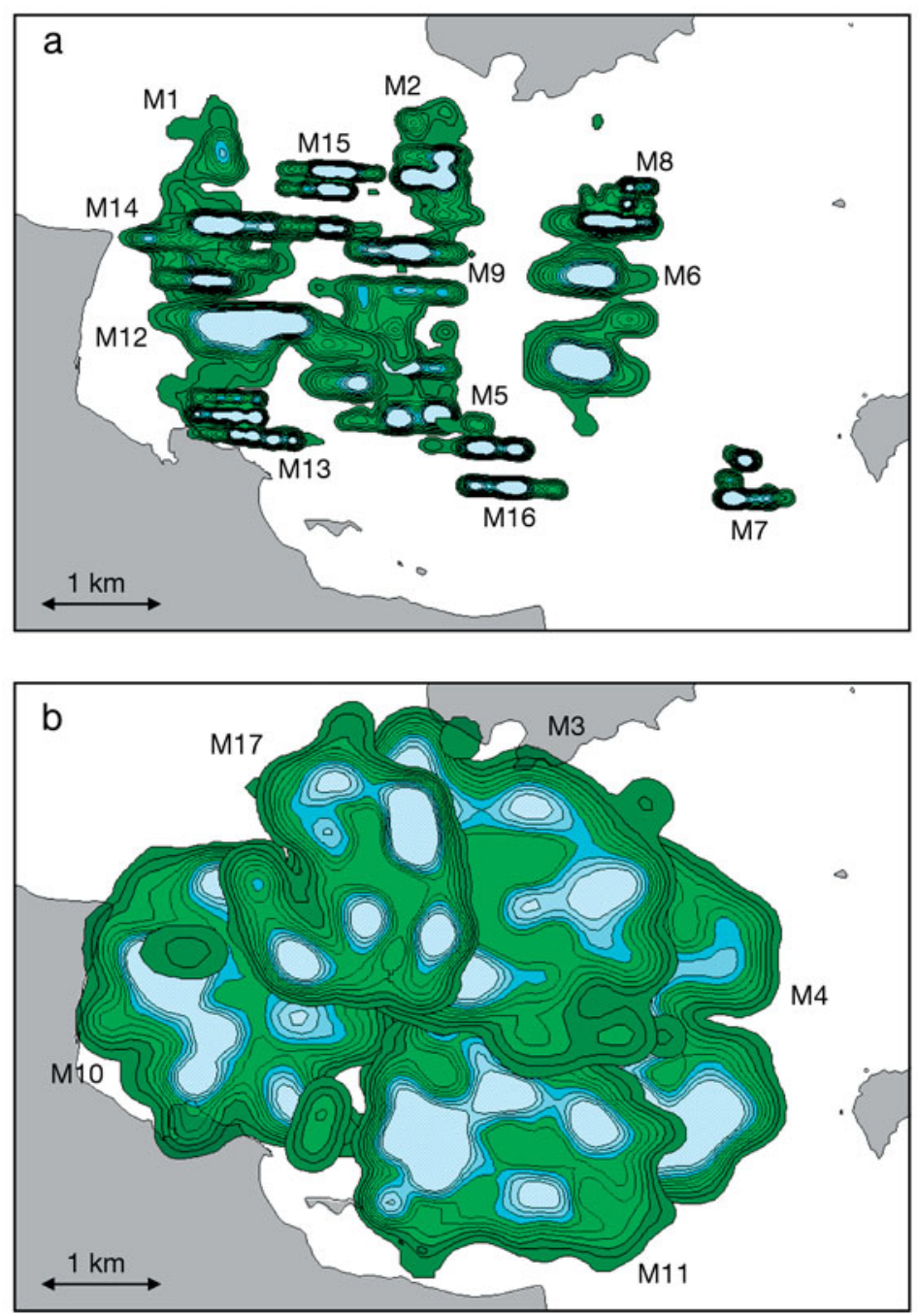

Fig. 5. Kernel home range plots of 50 to $95 \%$ isopleths, represented by the different colour shades, for the trill locations, as calculated using 3 archival acoustic hydrophones, of (a) 12 individual territorial male bearded seals with small areas and (b) 5 roaming males with large areas in Svalbard, Norway $78^{\circ} 55^{\prime} \mathrm{N}, 11^{\circ} 56^{\prime} \mathrm{E}$ (reproduced from Van Parijs et al. 2004) 
mated Identification System. In addition, the Northeast US Right Whale Sighting Advisory System (SAS) was created in 1996 to monitor right whale populations within the northeast waters of the United States (http:// rwhalesightings.nefsc.noaa.gov/). The SAS provides sighting information from aerial and shipboard surveys to commercial ships and mariners. The positions and maps of right whale sightings are distributed through various means: faxes and verbal updates to commercial vessels, $24 \mathrm{~h}$ radio broadcasts and online postings to several web pages. Due to logistical and weather constraints, however, it is estimated that only $33 \%$ of all whales are detected on a given day.
To improve the detection of right whales, Cornell University's Bioacoustics Research Program (BRP) developed a real-time passive acoustic buoy system that recognizes right whale upcalls using an automated detection program and relays these detections to the BRP (Fig. 7). Detections are then checked for accuracy, uploaded onto a web server and directly forwarded to the SAS and other parties for management and mitigation purposes (www.listenforwhales. org). The real-time buoy system continuously updates the presence of this species, and is a benchmark example of using passive acoustics for conservation purposes.

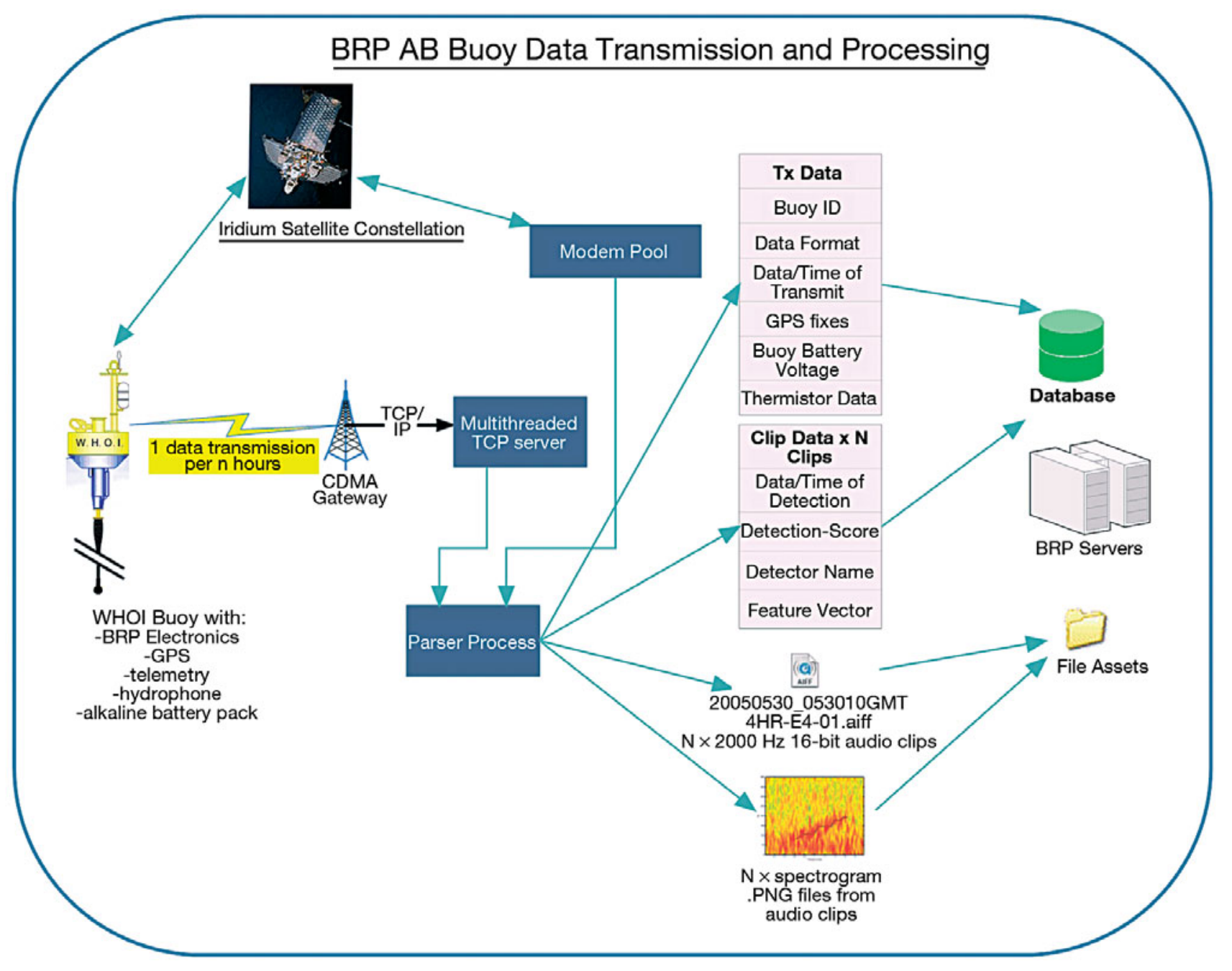

Fig. 6. Schematic diagram of an auto-buoy communications and server system that accepts and unwraps incoming data packets from multiple buoys via multiple cell phones and provides these data to a web server (see Fig. 7) that can be viewed over the internet. The auto-buoy hard ware was developed by Woods Hole Oceanographic Institute (WHOI), and contains electronics developed by the Bioacoustics Research Program at the Cornell University Laboratory of Ornithology (BRP), a global positioning system (GPS), a VHF telemetry receiver, an HTI hydrophone and an alkaline battery pack. Short sound clips of North Atlantic right whale up-call detections, with accompanying buoy information data such as buoy ID, location and voltage, are sent through GPS to an iridium satellite and via radio signal using a code division multiple channel access method (CDMA). The data then either pass through a modem pool or a multithreaded transmission control protocol (TCP) server. The data is subdivided into 2 categories separating sound clip data from the other data streams. These are then stored on a central data base and loaded onto a web server 


\section{Real-time PAM of Antarctic pinnipeds and other marine animals}

Real-time passive acoustic arrays can provide valuable long-term acoustic monitoring data in remote areas such as the Arctic and Antarctic. The Perennial Acoustic Observatory in the Antarctic Ocean (PALAOA) is an example of a stationary autonomous listening station that continuously records underwater sound year-round. The PALAOA observatory is located at $70^{\circ} 31^{\prime} \mathrm{S}, 8^{\circ} 13^{\prime} \mathrm{W}$, on the Ekström Ice Shelf, eastern Weddell Sea, $1 \mathrm{~km}$ from the ice shelf edge and $15 \mathrm{~km}$ from Neumayer Base (the German Antarctic research station). PALAOA consists of a $520 \mathrm{~m}$ baseline tetrahedral hydrophone array $\underline{2}$ deployed through boreholes underneath the 100 m-thick floating Antarctic ice shelf (Boebel et al. 2006, Klinck 2008). The observatory is energetically self-sustained utilizing solar and wind energy, and has operated since December 2005. The PALAOA system enables real-time acquisition of data which are subsequently transferred via live feed from the Neumayer Base to the Alfred Wegener Institute in Germany (www.awi.de/en/research/new_ technologies/marine_observing_systems/ocean_ acoustics/palaoa/palaoa_livestream). A main reason for incorporating real-time data transfer in the PALAOA system was to allow autonomous and continuous recording over long time spans without any limitation on onsite data storage (Boebel et al. 2006, Klinck 2008, Van Opzeeland et al. 2008).

The PALAOA recordings contain a variety of cetacean vocalizations, as well as vocalizations of 4 Antarctic pinniped species: Weddell Leptonychotes weddellii, Ross Ommatophoca rossii, crabeater Lobodon carcinophaga and leopard seals Hydrurga leptonyx (Fig. 8). The latter 3 species breed on pack-ice, and many aspects of the basic ecology of these species are still largely unknown due to the inaccessibility of their habitat. All 4 species exhibit species-specific vocal repertoires and have distinct patterns in their vocalization activity. Fig. 8 illustrates the call activity of all 4 species during 4 d in December 2006. Weddell seal call activity declined towards the end of December, which is near the end of the Weddell seal mating season (e.g. Bartsh et al. 1992, Harcourt et al. 1998, 2000). In contrast, Ross seal vocal activity started and increased throughout December. Crabeater seal call

25ince mid-2006 the failure of 2 hydrophones has reduced the array to a 2 -channel system activity was very low, with calls only present in early December; higher call rates have been documented during October and November (Thomas \& DeMaster 1982). Although Thomas \& DeMaster (1982) reported that the peak underwater vocalization period for leopard seals coincided with that of crabeater seals, the PALAOA recordings show a relatively constant call rate in December for leopard seals. Acoustic analyses of PALAOA recordings over longer time spans are underway and will provide further insights into the acoustic behavior and ecology of all 4 pinniped species. The PALAOA recordings will also be used to develop an ocean noise budget and to monitor the effects of anthropogenic sounds (e.g. ice breakers, scientific sound sources) on marine mammal calling behavior.

\section{Towed array applications}

Real-time detection of cetaceans using passive acoustics is increasingly recognized as a potential tool for the mitigation of human impacts on the marine environment (Barlow \& Gisiner 2006, Castellote 2007, Potter et al. 2007, Weir \& Dolman 2007). The successful

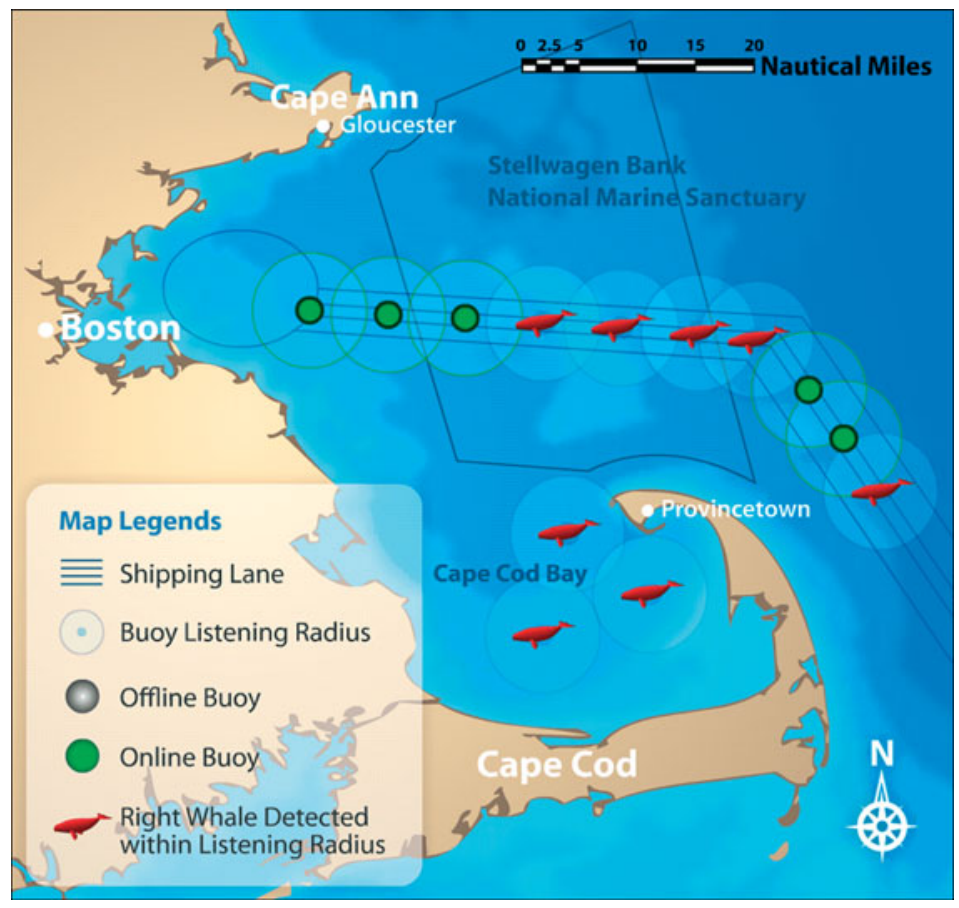

Fig. 7. Screen shot of the real-time auto buoy system that is operational off the northeast coast of the USA aimed at increasing the efficiency of the alerting system directed towards mariners entering into the area with the intention of reducing vessel speeds and thereby preventing ship strikes (see www.listenforwhales.org). Note that in this screen shot there are no offline buoys, indicating that at this point in time all buoys are functional and actively listening for North Atlantic right whale up-calls 

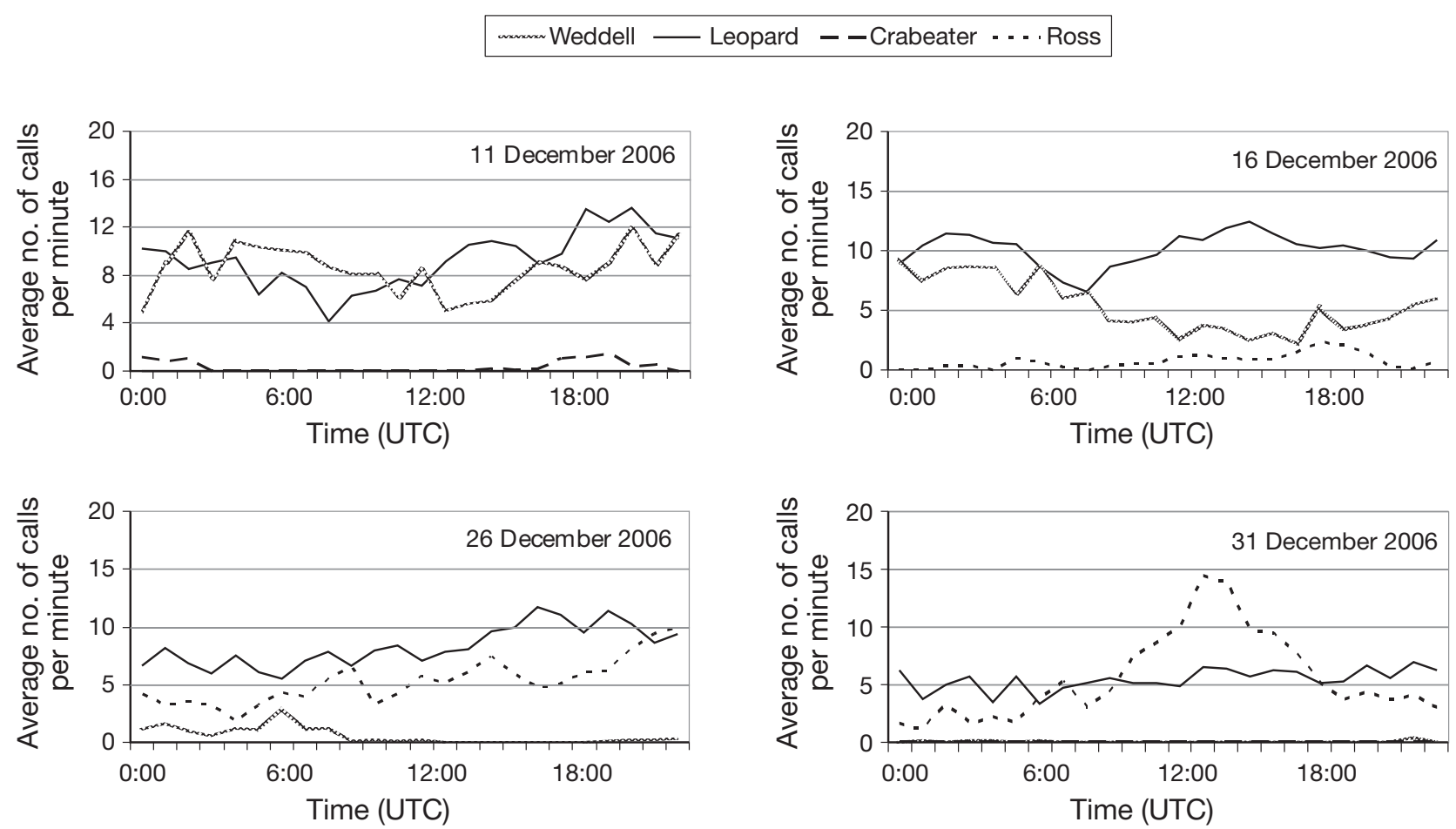

Fig. 8. Preliminary analyses of 4 days of real-time passive acoustic recordings made using the Perennial Acoustic Observatory in the Antarctic Ocean in December 2006. Results show different patterns of temporal variation in vocal activity of Weddell, leopard, crabeater and Ross seals. Average number of calls per minute is based on 10 min counts for each hour

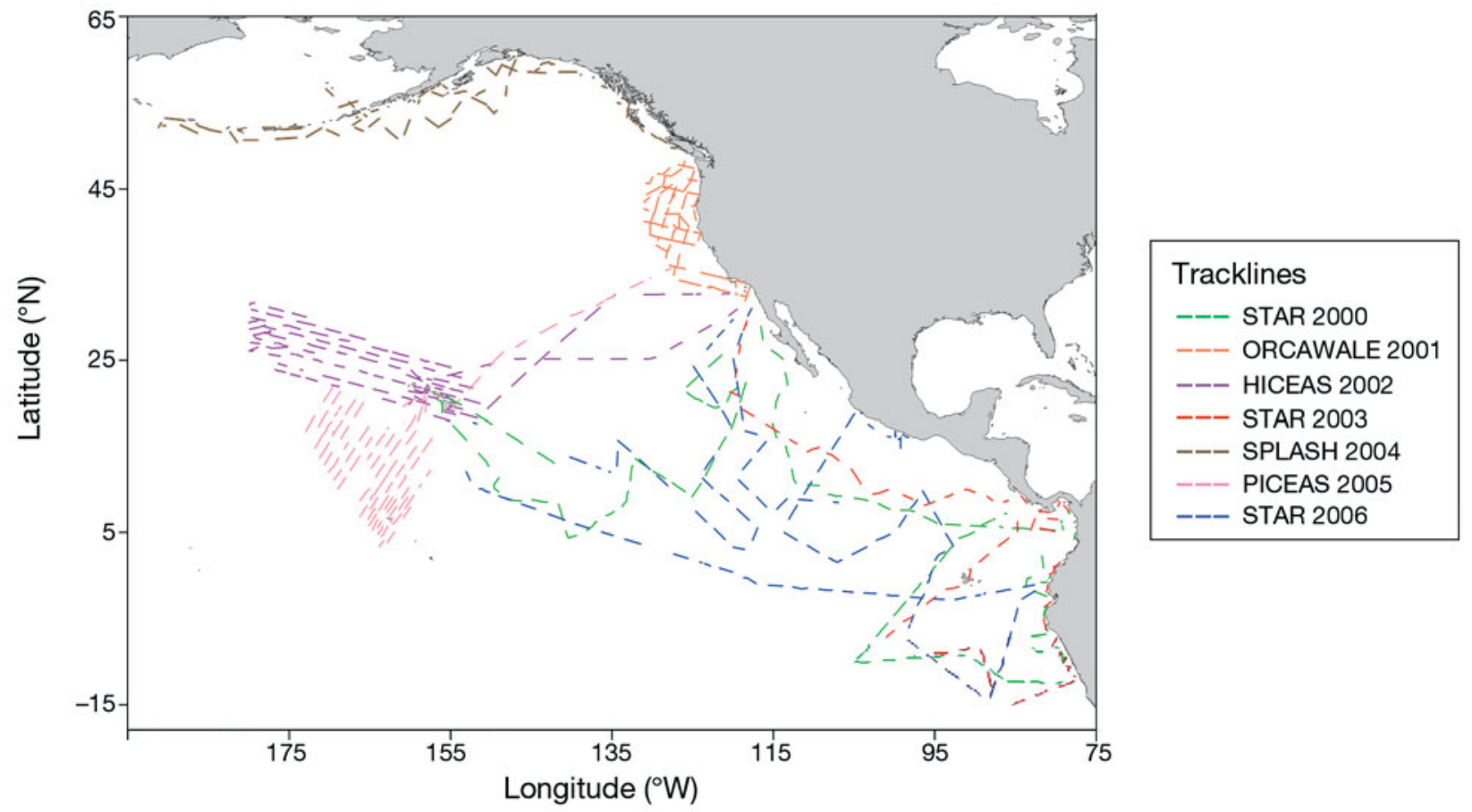

Fig. 9. Study area for 7 shipboard visual and acoustic cetacean surveys with tracklines of acoustic monitoring using a towed hydrophone array. Total distance surveyed for all tracklines combined is $46370 \mathrm{~km}$ 


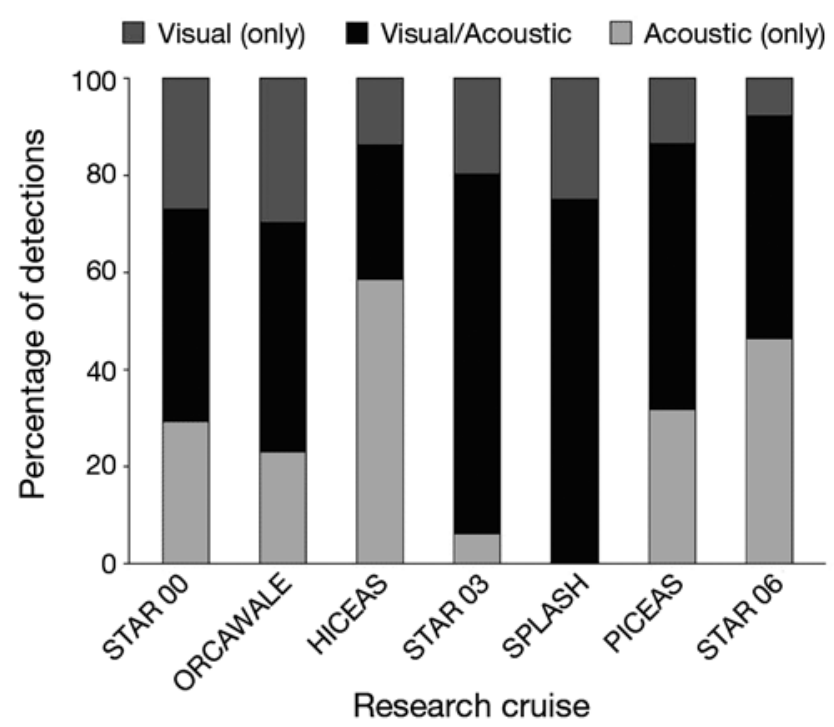

Fig. 10. Percentage of dolphin detections made by the visual observation team (dark gray), the acoustic detection team (light grey) and both the visual and acoustic detection teams (black) during 7 visual and acoustic cetacean surveys conducted by the Southwest Fisheries Science Center

use of towed arrays for this purpose requires that survey designs take account of the types of anthropogenic impacts, the range of detections and the vocal behaviors of animals. Ideally, such surveys should include pre-, during- and post-operation components (Castellote 2007). It is also important that complementary monitoring methods be used in such surveys -

Table 1. Mean acoustic detection distances for single-species groups of dolphins, minke whales Balaenoptera acutorostrata and sperm whales Physeter macrocephalus for Southwest Fisheries Science Center research cruises years 2000-2007, inclusive

\begin{tabular}{|lcccl|}
\hline \multirow{2}{*}{ Taxon } & \multicolumn{4}{c}{ Detection distance (nautical miles) } \\
& Sample size & Mean & SD & Range \\
\hline Lissodelphis borealis & 5 & 0.58 & 0.67 & $0.1-1.5$ \\
Lagenorhynchus obliquidens & 4 & 0.71 & 0.87 & $0.1-2$ \\
Orcinus orca & 19 & 0.73 & 0.71 & $0.1-2.3$ \\
Grampus griseus & 24 & 0.95 & 0.7 & $0.026-2.3$ \\
Lagenorhynchus obscurus & 3 & 0.98 & 1.32 & $0.01-2.5$ \\
Feresa attenuata & 2 & 1.00 & 1.05 & $0.26-1.75$ \\
Berardius bairdii & 2 & 1.10 & 0.84 & $0.5-1.7$ \\
Steno bredanensis & 28 & 1.53 & 1.19 & $0.01-4.5$ \\
Tursiops truncatus & 53 & 1.79 & 1.33 & $0.08-6$ \\
Stenella attenuata & 71 & 1.85 & 1.53 & $0.01-6$ \\
Lagenodelphis hosei & 1 & 2.00 & - & - \\
Delphinus spp. & 112 & 2.22 & 1.6 & $0.1-6$ \\
Globicephala spp. & 48 & 2.56 & 1.77 & $0.1-8.5$ \\
Stenella longirostris & 35 & 2.61 & 1.55 & $0.1-6$ \\
Stenella coeruleoalba & 136 & 2.63 & 1.84 & $0.1-10$ \\
Pseudorca crassidens & 14 & 2.93 & 1.52 & $1-6$ \\
Balaenoptera acutorostrata & 55 & 3.90 & 1.7 & $0.5-8$ \\
Physeter macrocephalus & 231 & 5.90 & 4.2 & $0.7-21$ \\
\hline
\end{tabular}

such as static acoustic monitoring (for increased temporal coverage) and visual observations (to account for biases due to silent animals).

A single towed hydrophone array consisting of at least 2 hydrophones can be used to obtain bearing angles to a sound source; convergence of bearing angles as the ship travels allows for localizations of the sound source with a left/right ambiguity. This ambiguity can be resolved by integration of a second array, offset from the first, or by a change in the direction of travel of the ship. While towed arrays have been used for detection of baleen whales (Clark \& Fristrup 1997), dolphins (Rankin et al. 2008a) and porpoise (Akamatsu et al. 2001, Li et al. 2009), there are some limitations to its practical use. Several studies have shown that cetaceans respond to survey vessels, which may affect their vocal behavior (Au \& Perryman 1982, Hewitt 1985). Also, a recent study has found a decrease in acoustic detection of dolphins forward of the vessel when using towed hydrophone arrays (Rankin et al. 2008b).

Passive acoustic detection of cetaceans using towed hydrophone arrays has yielded new insights into the acoustic behavior of several species. In 2002, passive acoustic detection and localization identified the mysterious 'boing' sound in the Pacific Ocean as emanating from minke whales (Gedamke et al. 2001, Rankin $\&$ Barlow 2005). The match of this sound to minke whales allowed researchers to gain additional understanding of the distribution, migration and stock structure of this species (Rankin \& Barlow 2005).

Recent analyses of the vocal behavior of dolphins in the North Pacific have shown a strong correlation between group size, geographic range and vocal behavior (Rankin et al. 2008b). This correlation may indicate evolutionary changes that relate group size to vocal behavior. Since 2000, the NOAA's Southwest Fisheries Science Center has conducted combined visual and acoustic line-transect cetacean surveys covering a significant portion of the North Pacific Ocean (Fig. 9). The need to use towed hydrophone arrays in these population surveys was highlighted when it was recognized that a large number of dolphins were missed using only visual observations; for example, during the 2002 HICEAS survey, over $58 \%$ of the dolphin schools were only detected acoustically (Fig. 10, Table 1). However, the complex vocal behavior of dolphins has made species identification challenging. Nonetheless, recent improvements in the acoustic classification of dolphin whistles permitted 
the acoustic detection and localization of false killer whales Pseudorca crassidens during a recent survey dedicated to this species (Barlow \& Rankin 2007, Oswald et al. 2007b). Future improvements in acoustic species classification will allow for continued integration of towed hydrophone arrays in shipboard surveys.

Not all species are difficult to identify based on their vocalizations. Because sperm whale vocalizations are easily identifiable and accurate group size estimates can also be obtained under most conditions, the use of towed hydrophone arrays has improved the estimation of total abundance for this species (Barlow \& Taylor 2005). For species that are difficult to detect using traditional visual observation methods (such as minke whales), passive acoustics may be the only reasonable approach for population estimation (Rankin \& Barlow 2005, Rankin et al. 2007b). Overall, the use of towed hydrophone arrays combined with visual observations has generated a large number of descriptions of vocalizations of various species which otherwise would not have been possible (Oswald et al. 2007a, Rankin et al. 2007a).

\section{OUTLOOK}

Passive acoustic technologies have been revolutionized during the last decade, in terms of both hardware and software. Archival and real-time passive acoustic arrays are now among the lowest cost approaches for mesoscale monitoring of marine areas and can be used to monitor vocal marine life in areas difficult to survey by traditional visual methods. Fixed autonomous passive acoustic arrays sample continuously for prolonged periods of time, allowing assessment of seasonal changes in distribution and acoustic behavior of individuals without introducing into the environment the types of disturbances generated by the presence of survey vessels or aircrafts. Unlike more traditional visual methods, passive acoustic technologies can survey in darkness and remain active during adverse weather conditions. Further, the ability to retrieve and redeploy archival ARUs provides a level of flexibility in data acquisition that is not available with other fixed longterm monitoring systems. Units can be deployed for short periods (days to weeks) or longer periods (months to years) with variable sampling rates. Realtime acoustic buoys, capable of relaying information almost instantaneously to a wide range of stakeholders, have recently shown their potential for enabling responsive management and mitigation of marine animals at the mesoscale level. Although these techniques have primarily been used with cetaceans, the potential now exists for studying many other marine animals such as pinnipeds, sirenians and fishes. However, there are still major hardware and software hurdles to overcome. Similarly, acoustic information can easily be misleading and interpreted incorrectly. PAM is only really useful when taken in the context of the acoustic behavioral ecology of the animals and applied in a regional and seasonally appropriate context. In order to improve PAM, more information is needed on individual, group, population and species sound level usage.

Acknowledgements. We thank B. Southall, D. Nowacek and $H$. Browman for the insight and innovation which made this theme section on passive acoustics possible. An immense number of people contributed to making the case studies in this manuscript happen. However, the hardware and software that were predominately used in these case studies was developed at the Bioacoustics Research Program at Cornell University, without which passive acoustics would not be what it is today. The hardware and software for the towed array studies are the result of a collaborative effort between J. Barlow, J. Oswald, D. K. Mellinger and S. Rankin. Funding for these case studies was received from Abrolhos National Marine Park, Animal Behavior Society, Brazilian Government (CAPES PhD Fellowship to R.S.S.L.), Brazilian Navy, Canon National Parks Science Scholars Program, Cornell University Lab of Ornithology, European Union Marie Curie Postdoctoral, Instituto Baleia Jubarte, Petróleo Brasileiro S.A. (PETROBRAS), Massachusetts Department of Marine Fisheries, NOAA National Marine Fisheries Service (NEFSC \& SEFSC), Norwegian National Research Council, Norwegian Polar Institute, Ny- Alesund Large Scale Facility for Arctic Environmental Research and University Studies on Svalbard, US Navy and Alfred Wegener Institute for Polar and Marine Research. We also thank the 3 reviewers who struggled through a much rougher version of this manuscript and who we hope will find the end result a significant improvement as a result of their input.

\section{LITERATURE CITED}

Akamatsu T, Wang D, Wang K, Wei Z (2001) Comparison between visual and passive acoustic detection of finless porpoise in the Yangtze River, China. J Acoust Soc Am 109:1723-1727

Anderson PK, Barclay RMR (1995) Dugong acoustic signals: physical characteristics, individual differences, and behavioral correlates. J Mammal 76:1226-1237

Au D, Perryman W (1982) Movement and speed of dolphin schools responding to an approaching ship. Fish Bull 80: 371-379

Barlow J, Gisiner R (2006) Mitigating, monitoring and assessing the effects of anthropogenic sound on beaked whales. J Cetacean Res Manag 7:239-249

Barlow J, Rankin S (2007) False killer whale abundance and density: preliminary estimates for the PICEAS study area south of Hawaii and new estimates for the US EEZ around Hawaii. SWFSC Admin Report LJ-07-02

Barlow J, Taylor BL (2005) Estimates of sperm whale abundance in the northeastern temperate Pacific from a combined acoustic and visual survey. Mar Mamm Sci 21: $429-445$

Barnes CR, Best MMR, Bornhold BD, Juniper SK, Pirenne B, Phibbs P (2007) The NEPTUNE Project — a cabled ocean observatory in the NE Pacific: overview, challenges and scientific objectives for the installation and operation of 
Stage I in Canadian waters. Symposium on Underwater Technology and Workshop on Scientific Use of Submarine Cables and Related Technologies, Tokyo, Japan. IEEE Press, Piscataway, NJ

Bartsh SS, Johnston SD, Siniff DB (1992) Territorial behavior and breeding frequency of male Weddell seals (Leptonychotes weddellii) in relation to age, size, and concentration of serum testosterone and cortisol. Can J Zool 70: 680-692

Boebel O, Kindermann L, Klinck H, Bornemann H and others (2006) Real-time underwater sounds from the Southern Ocean. Eos Trans Am Geophys Union 87:361-362

Brown MW, Allen JM, Kraus SD (1995) The designation of seasonal right whale conservation zones in the waters of Atlantic Canada. In: Shackell NL, Willison MJH (eds) Marine protected areas and sustainable fisheries. Proceedings of a symposium on marine protected areas and sustainable fisheries conducted at the Second International Conference on Science and the Management of Protected Areas. Science and Management of Protected Areas Association, Wolfville, NS

Capet X, Mcwilliams JC, Mokemaker MJ, Shchepetkin AF (2008) Mesoscale to submesoscale transition in the California current system. Part I: flow structure, eddy flux, and observational tests. J Phys Oceanogr 38:29-43

Casaretto L, Hawkins AD (2002) Spawning behaviour and the acoustic repertoire of haddock. Bioacoustics 12:250-252

Castellote M (2007) General review of protocols and guidelines for minimizing acoustic disturbance to marine mammals from seismic surveys. J Int Wildl Law Policy 10:273-288

Clark CW, Fristrup KM (1997) Whales 95: a combined visual and acoustic survey of blue and fin whales off southern California. Rep Int Whaling Comm 47:583-600

Clark CW, Gillespie D, Nowacek DP, Parks SE (2007) Listening to their world: acoustics for monitoring and protecting right whales in an urbanized ocean. In: Kraus SD, Rolland RM (eds) The urban whale: North Atlantic right whales at the crossroads. Harvard University Press, Cambridge, MA, p 333-357

Colton JB Jr (1972) Temperature trends and the distribution of groundfish in continental shelf waters, Nova Scotia to Long Island. Fish Bull 70:637-658

Darling JD, Sousa-Lima RS (2005) Songs indicate interaction between humpback whale (Megaptera novaeangliae) populations in the Western and Eastern South Atlantic Ocean. Mar Mamm Sci 21:557-566

Figueroa H (2006) Extensible BioAcoustic Tool (XBAT). Available at: http://xbat.org/home.html

Gannon DP (2008) Passive acoustic techniques in fisheries science: a review and prospectus. Trans Am Fish Soc 137: 638-656

Gedamke J, Costa DP, Dunstan A (2001) Localization and visual verification of a complex minke whale vocalization. J Acoust Soc Am 109:3038-3047

Harcourt RG, Hindell MA, Waas JR (1998) Under ice movements and territory use in free-ranging Weddell seals during the breeding season. N Z Nat Sci 23:72-73

Harcourt RG, Hindell MA, Bell DG, Waas JR (2000) Threedimensional dive profiles of free-ranging Weddell seals. Polar Biol 23:479-487

> Harcourt RG, Kingston JJ, Waas JR, Hindell MA (2007) Foraging while breeding: Alternative mating strategies by male Weddell seals? Aquat Conserv 17:68-78

Hatch LT, Fristrup KM (2009) No barrier at the boundaries: implementing regional frameworks for noise management in protected natural areas. Mar Ecol Prog Ser 395:223-244

Hawkins AD, Amorim MCP (2000) Spawning sounds of male haddock, Melanogrammus aeglefinus. Environ Biol Fishes 59:29-41

> Hawkins AD, Chapman KJ, Symonds DJ (1967) Spawning of haddock in captivity. Nature 215:923-925

Hewitt R (1985) Reactions of dolphins to a survey vessel: effects on census data. Fish Bull 83:187-194

> Insley SJ, Phillips AV, Charrier I (2003) A review of social recognition in pinnipeds. Aquat Mamm 29:181-201

IWC (International Whaling Commission) (2001) Report of the workshop on status and trends of western North Atlantic right whales. J Cetacean Res Manag Spec Issue 2:1-87

Klinck H (2008) Automated detection, localization and identification of leopard seals. PhD thesis, University of Trier

Kraus SD, Hatch JJ (2001) Mating strategies in the North Atlantic right whale (Eubalaena glacialis). J Cetacean Res Manag Spec Issue 2:237-244

Kraus SD, Kenney RD (1991) Information on right whales (Eubalaena glacialis) in three proposed critical habitats in United States waters of the western North Atlantic Ocean. Publication No. PB91-194431, National Technical Information Services, Washington, DC

Kraus SD, Brown MW, Caswell H, Clark CW and others (2005) North Atlantic right whales in crisis. Science 309: $561-562$

Li S, Akamatsu T, Wang D, Wang A (2009) Localization and tracking of phonating finless porpoises using towed stereo acoustic data-loggers. J Acoust Soc Am 126:468-475

Luczkovich JJ, Sprague MW, Johnson SE, Pullinger RC (1999) Delimiting spawning areas of weakfish, Cynoscion regalis (Family Sciaenidae) in Pamlico Sound, North Carolina using passive hydroacousticsurveys. Bioacoustics 10:143-160

Luczkovich J, Mann D, Rountree R (2008) Passive acoustics as a tool in fisheries science. Trans Am Fish Soc 137:533-541

Mann DA, Lobel PS (1995) Passive acoustic detection of sounds produced by the damselfish, Dascyllus albisella (Pomacentridae). Bioacoustics 6:199-213

McCauley RD, Cato DH (2000) Patterns of fish calling in a nearshore environment in the Great Barrier Reef. Philos Trans R Soc Lond B 355:1289-1293

> Mellinger DK, Clark CW (2006) MobySound: a reference archive for studying automatic recognition of marine mammal sounds. Appl Acoust 67:1226-1242

Mellinger DK, Stafford KM, Moore SE, Dziak RP, Matsumoto $\mathrm{H}$ (2007) An overview of fixed passive acoustic observation methods for cetaceans. Oceanography 20:36-45

Moore SE, Stafford KM, Mellinger DK, Hildebrand JA (2006) Listening for large whales in the offshore waters of Alaska. BioScience 56:49-55

Noad MJ, Cato DH, Bryden MM, Jenner MN, Jenner KCS (2000) Cultural revolution in whale songs. Nature 408:537

Orlanski I (1975) A rational subdivision of scales for atmospheric processes. Bull Am Meteorol Soc 56:527-530

Oswald JN, Rankin S, Barlow J (2007a) First description of whistles of Pacific Fraser's dolphins Lagenodelphis hosei. Bioacoustics 16:99-111

> Oswald JN, Rankin S, Barlow J, Lammers MO (2007b) A tool for real time acoustic species identification of delphinid whistles. J Acoust Soc Am 122:587-595

Parks SE, Tyack PL (2005) Sound production by North Atlantic right whales (Eubalaena glacialis) in surface active groups. J Acoust Soc Am 117:3297-3306

> Parks SE, Hamilton PK, Kraus SD, Tyack PL (2005) The gunshot sound produced by male North Atlantic right whales (Eubalaena glacialis) and its potential function in reproductive advertisement. Mar Mamm Sci 21:458-475 Payne RS, McVay S (1971) Songs of humpback whales. 
Science 173:585-597

Petitt R, Harris D, Wooding B, Bailey J and others (2002) The Hawaii-2 Observatory. IEEE J Oceanic Eng 27:245-253

Potter JR, Thillet M, Douglas C, Chitre MA, Doborzynski Z, Seekings PJ (2007) Visual and passive acoustic marine mammal observations and high-frequency seismic source characteristics recorded during a seismic survey. IEEE J Oceanic Eng 32:469-483

Rankin S, Barlow J (2005) Source of the North Pacific 'boing' sound attributed to minke whales. J Acoust Soc Am 118: 3346-3351

Rankin S, Oswald JN, Barlow J, Lammers M (2007a) Patterned burst-pulse vocalizations of the northern right whale dolphin, Lissodelphis borealis. J Acoust Soc Am 121: 1213-1218

Rankin S, Norris TF, Smultea MA, Oedekoven C, Zoidis AM, Silva E, Rivers J (2007b) A visual sighting and acoustic detections of minke whales, Balaenoptera acutorostrata (Cetacea: Balaenopteridae), in nearshore Hawaiian waters. Pac Sci 61:395-398

Rankin S, Barlow J, Oswald J (2008a) An assessment of the accuracy and precision of localization of a stationary sound source using a 2-element towed hydrophone array. NOAA Tech Memo NOAA-TM-NMFS-SWFSC-416

Rankin S, Oswald JN, Barlow J (2008b) Acoustic behavior of dolphins in the Pacific Ocean: implications for using passive acoustic methods for population studies. Can Acoust 36:88-92

Redfern JV, Ferguson MC, Becker EA, Hyrenbach KD and others (2006) Techniques for cetacean habitat modeling. Mar Ecol Prog Ser 310:271-295

Reid JP, Rathbun GB, Wilcox JR (1991) Distribution patterns of individually identifiable West Indian manatees (Trichechus manatus) in Florida. Mar Mamm Sci 7:180-190

Saucier MH, Baltz DM (1993) Spawning site selection by spotted seatrout, Cynoscion nebulosus, and black drum, Pogonias cromis, in Louisiana. Environ Biol Fishes 36:257-272

Silber GK, Bettridge S (2006) United States' actions to reduce the threat of ship collisions with north Atlantic right whales. Paper IWC/58/CC8 presented at the IWC Scientific Committee, St. Kitts

Simard Y, Bahoura M, Park CW, Rouat J and others (2006) Development and experimentation of a satellite buoy network for real-time acoustic localization of whales in the St. Lawrence. Proc OCEANS '06 MTS/IEEE Sep 18-21, 2009, Boston, MA

Sousa-Lima RS (2007) Acoustic ecology of humpback whales (Megaptera novaeangliae) in the Abrolhos National Marine Park, Brazil. PhD dissertation, Cornell University, Ithaca, NY

Sousa-Lima RS, Clark CW (2008) Modeling the effect of boat traffic on singing activity of humpback whales (Megaptera novaeangliae) in the Abrolhos National Marine Park, Brazil. Can Acoust 36:174-181

Sousa-Lima RS, Clark CW (2009) Whale sound recording technology as a tool for assessing the effects of boat noise in a Brazilian Marine Park. Park Sci 26:59-63

Sousa-Lima RS, Paglia AP, da Fonseca GAB (2002a) Signature information and individual recognition in the isolation calls of Amazonian manatees, Trichechus inunguis (Mammalia: Sirenia). Anim Behav 63:301-310

Sousa-Lima RS, Morete ME, Fortes RC, Freitas AC, Engel MH (2002b) Impact of boats on the vocal behavior of hump- back whales off Brazil. J Acoust Soc Am 112:2430-2431

Sousa-Lima RS, Paglia AP, da Fonseca GAB (2008) Gender, age, and identity in the isolation calls of Antillean manatees (Trichechus manatus manatus). Aquat Mamm 34: 109-122

Thomas JA, DeMaster DP (1982) An acoustic technique for determinig diurnal activities in leopard (Hydrurga leptonyx) and crabeater (Lobodon carcinophagus) seal. Can J Zool 60:2028-2031

Tyack PL (1981) Interactions between singing Hawaiian humpback whales and conspecifics nearby. Behav Ecol Sociobiol 8:105-166

Tyack PL (2000) Functional aspects of cetacean communication. In: Mann J, Connor RC, Tyack PL, Whitehead H (eds) Cetacean societies: field studies of dolphins and whales. University of Chicago Press, Chicago, IL, p 270-307

Urazghildiiev IR, Clark CW (2006) Acoustic detection of North Atlantic right whale contact calls using the generalized likelihood ratio test. J Acoust Soc Am 120: 1956-1963

Vanderlaan ASM, Taggart CT (2007) Vessel collisions with whales: the probability of lethal injury based on vessel speed. Mar Mamm Sci 23:144-156

Van Opzeeland IC, Kindermann L, Boebel O, Van Parijs SM (2008) Insights into the acoustic behaviour of polar pinnipeds: current knowledge and emerging techniques of study. In Weber EA, Krause LH (eds) Animal behaviour: new research. Nova Science Publishers, New York, p 133-161

Van Parijs SM (2003) Aquatic mating in pinnipeds: a review. Aquat Mamm 29:214-226

Van Parijs SM, Clark CW (2006) Long term mating tactics in an aquatic mating pinniped: the bearded seal, Erignathus barbatus. Anim Behav 72:1269-1277

Van Parijs SM, Janik VM, Thompson PM (2000) Display area size, tenure length and site fidelity in the aquatically mating male harbour seal. Can J Zool 78:2209-2217

> Van Parijs SM, Lydersen C, Kovacs KM (2003) Vocalizations and movements suggest alternative mating tactics in male bearded seals. Anim Behav 65:273-283

> Van Parijs SM, Lydersen C, Kovacs KM (2004) The effects of ice cover on the behaviour of aquatic mating male bearded seals. Anim Behav 68:89-96

Wade $\mathrm{P}$, Heide-Jørgensen M, Shelden $\mathrm{K}$, Barlow J and others (2006) Acoustic detection and satellite-tracking leads to discovery of rare concentration of endangered North Pacific right whales. Biol Lett 2:417-419

> Ward-Geiger LI, Silber GK, Baumstark RD, Pulfer TL (2005) Characterization of ship traffic in right whale critical habitat. Coast Manag 33:263-278

Weinrich MT, Kenney RD, Hamilton PK (2000) Right whales (Eubalaena glacialis) on Jeffreys Ledge: A habitat of unrecognized importance? Mar Mamm Sci 16:326-337

> Weir CR, Dolman SJ (2007) Comparative review of the regional marine mammal mitigation guidelines implemented during industrial seismic surveys, and guidance towards a worldwide standard. J Int Wildl Law Policy 10: $1-27$

Wiens JA (1989) Spatial scaling in ecology. Funct Ecol 3: 385-397

> Winn HE, Winn LK (1978) The song of the humpback whale Megaptera novaeangliae in the West Indies. Mar Biol 47: 97-114 